\title{
Skin secretion of Siphonops paulensis (Gymnophiona, Amphibia) forms voltage-dependent ionic channels in lipid membranes
}

E.F. Schwartz ${ }^{1}$, A. Stucchi-Zucchi ${ }^{2}$, C.A. Schwartz ${ }^{1}$ and L.C. Salomão ${ }^{2}$

\author{
${ }^{1}$ Laboratório de Toxinologia, Departamento de Ciências Fisiológicas, \\ Instituto de Ciências Biológicas, Universidade de Brasília, Brasília, DF, Brasil \\ ${ }^{2}$ Departamento de Fisiologia, Instituto de Biociências, Universidade de São Paulo, \\ São Paulo, SP, Brasil
}

\begin{abstract}
Correspondence

E.F. Schwartz

Laboratório de Toxinologia

Departamento de Ciências

Fisiológicas, UNB

70910-900 Brasília, DF

Brasil

Fax: +55-61-274-1141

E-mail: efschwa@unb.br

Publication supported by FAPESP.

Received October 14, 2002

The effect of the skin secretion of the amphibian Siphonops paulensis was investigated by monitoring the changes in conductance of an artificial planar lipid bilayer. Skin secretion was obtained by exposure of the animals to ether-saturated air, and then rinsing the animals with distilled water. Artificial lipid bilayers were obtained by spreading a solution of azolectin over an aperture of a Delrin cup inserted into a cut-away polyvinyl chloride block. In 9 of 12 experiments, the addition of the skin secretion to lipid bilayers displayed voltage-dependent channels with average unitary conductance of $258 \pm 41.67 \mathrm{pS}$, rather than nonspecific changes in bilayer conductance. These channels were not sensitive to 4-acetamido-4'-isothiocyanatostilbene-2,2'-disulfonic acid or tetraethylammonium ion, but the experimental protocol used does not permit us to specify their characteristics.
\end{abstract}

Accepted May 13, 2003
Amphibian skin secretion is considered to be a rich source of bioactive substances, which include biogenic amines, sterols, alkaloids, peptides, and proteins. These compounds have different biological activities, such as, myo-, cardio-, or neurotoxic, cholinomimetic, sympathomimetic, anesthetic, hemolytic, hallucinogenic, cytotoxic, and antibiotic activities (1). Most studies have focused on anuran species, whereas there are only a few studies on the toxicity of the skin of caecilian amphibians, although in 1940 Sawaya (2) demonstrated the cardiotoxicity of the skin secretion of Siphonops annulatus. A similar cardiotoxic action of S. paulensis skin secretion on toad heart bioassays was reported more recently (3). It was shown that the blockade of electrical activity of toad
Key words

- Siphonops

- Toxin

- Channel-forming toxins

- Skin secretion

- Ion channel

- Hemolysin heart was due to the hemolytic activity on red blood cells, leading to an increase in $\mathrm{K}^{+}$ concentration in the medium (4). It was also shown that the treatment of $S$. paulensis skin secretion with red blood cell ghosts inhibited hemolysis (3). On the basis of these results, we decided to investigate the effect of $S$. paulensis skin secretion on the conductance of planar lipid membranes.

Adult $S$. paulensis were collected in Formosa (GO, Brazil), and maintained alive in native soil in the Laboratory of Toxinology, University of Brasília. In order to obtain the skin secretion the animals were carefully washed with distilled water and exposed to diethyl ether-saturated air in a closed container. Then, the animals were rinsed with distilled water. The protein content of the $S$. 
Figure 1. Typical example of the channel activity formed by toxin(s) from skin secretion of Siphonops paulensis incorporated into the lipid bilayer. The channel clearly shows voltage dependence. In $C$, the channel is in the closed state, and in $O$ the channel is open. paulensis skin secretion was measured (5) using bovine serum albumin as a standard and was used as reference for toxin content. Artificial lipid bilayers were obtained by spreading a solution of azolectin dissolved in n-decane $(10 \mathrm{mg} / \mathrm{ml})$ over an aperture $(0.33 \mathrm{~mm})$ of a Delrin cup, which was inserted into a cut-away polyvinyl chloride block, delimiting two compartments, i.e., cis-side and trans-side. These two chambers were filled with $3.5 \mathrm{ml}$ each of buffered salt solutions, pH 7 (10 mM HEPES-Tris), of the following compositions: $150 \mathrm{mM} \mathrm{KCl}, 15$ $\mathrm{mM} \mathrm{NaCl}$ plus $100 \mu \mathrm{M} \mathrm{CaCl}_{2}$ on the cisside, and $150 \mathrm{mM} \mathrm{NaCl}, 15 \mathrm{mM} \mathrm{KCl}$ plus $100 \mu \mathrm{M} \mathrm{CaCl}_{2}$ on the trans-side. Membrane formation was followed by measuring membrane capacitance. After the addition of 10 $\mu \mathrm{l}$ of $S$. paulensis skin secretion solution to the cis-compartment, changes in bilayer conductance were monitored using an Axopatch 200A amplifier, visualized on a digital oscilloscope (Gould Instruments Systems, Valley View, OH, USA), and recorded in digital form on videotape (Sharp, Mahwah, NJ, USA) employing an analog-digital converter (PCMb2, Medical Systems Corp., Greenvale, NY, USA). For analysis, the analog signal derived from the digital record was passed through an 8-pole Bessel filter, with the corner frequency $(-3 \mathrm{~dB})$ set at $500 \mathrm{~Hz}$, digitized using an analog interface (Digidata

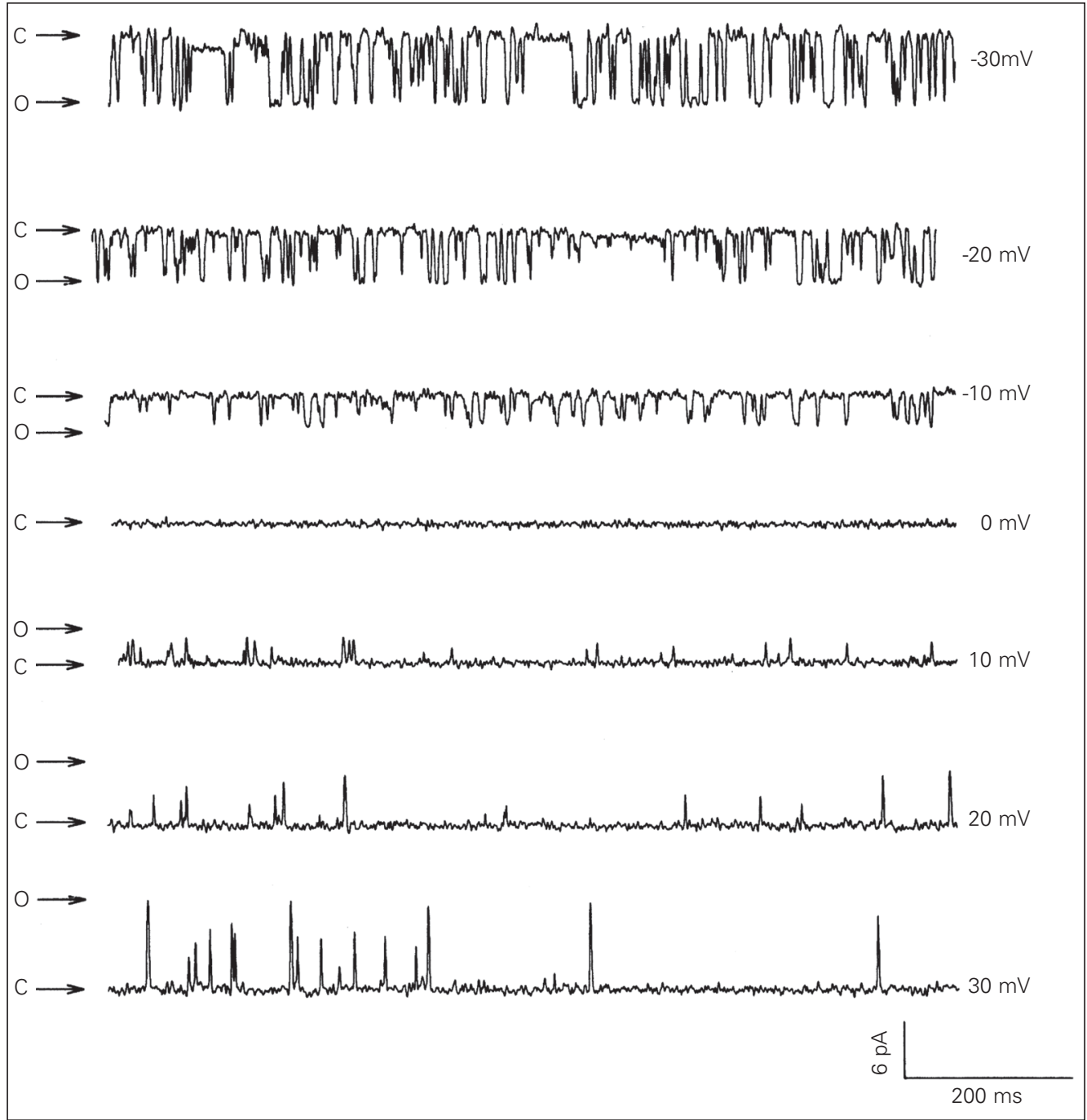


1200, Union City, CA, USA) at a frequency of $3000 \mathrm{~Hz}$ and recorded directly on a personal computer. Data were analyzed using the pCLAMP-6 system (Axon Instruments, Union City, CA, USA). $V_{c}$ corresponds to the potential difference between the $c i s$ - and the trans-side (ground). By convention, a positive current reflects the flow of cations from the cis- to the trans-compartment or the flow of anions in the opposite direction.

In 9 of 12 experiments, addition of $S$. paulensis skin secretion at a final concentration of $6.4 \mu \mathrm{g} / \mathrm{ml}$ to the cis-compartment of the lipid bilayer led to changes in membrane conductance. However, instead of nonspecific changes, typical channel activities were observed up to 15 min after the addition of $S$. paulensis skin secretion (Figure 1). Moreover, the activity of the channel was voltage-dependent. Clearly, the open probability is reduced as the voltage increases over the range of $-30 \mathrm{mV}$ to $30 \mathrm{mV}$. Near zero $\mathrm{mV}$ and at positive voltages, transitions to the open state were greatly reduced (Figure 2A). When the voltage was clamped at zero there was no current, although the asymmetrical distribution for sodium and potassium provided chemical gradients for ion flows. Tetraethylammonium ion (TEA, $0.1 \mathrm{mM}$, added to the ciscompartment), a potassium channel blocker, had no effect on open probability. A commonly used chloride channel blocker, 4acetamido-4'-isothiocyanatostilbene-2,2'-

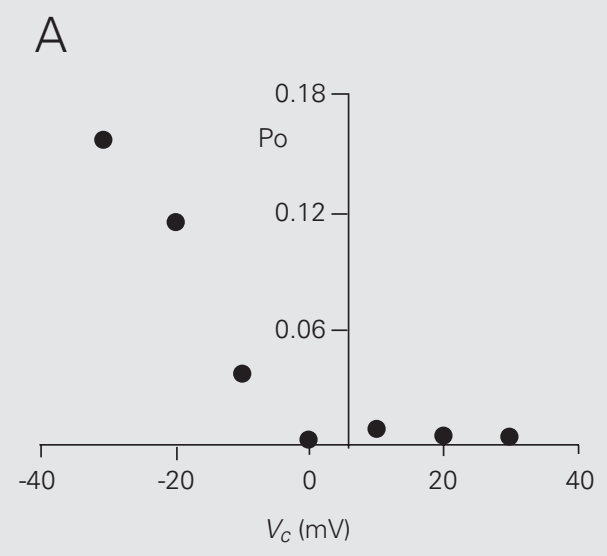

disulfonic acid (SITS, $1 \mathrm{mM}$, added to the ciscompartment) did not modify the channel activity. A typical current-voltage relation for a single channel is plotted in Figure 2B. Under the experimental conditions used, the $I_{c} v s V_{c}$ relations were nearly linear. From the slope of the linear regression curve of the $I_{c} v s V_{c}$ relations the single channel conductance averaged $258 \pm 41.67 \mathrm{pS}(\mathrm{N}=6)$.

Lysins have been isolated from the venom of different animals, as well as from bacteria. Some of them have been shown to cause lysis by opening pores, or forming channels in the cell membrane. Cecropins (6), $\delta$-toxin from Staphylococcus aureus (7), Actinobacillus pleuropneumoniae exotoxins (8), Bordetella pertussis adenylate cyclase toxin (9), Vibrio cholerae hemolysin (10), Escherichia coli $\alpha$ hemolysin (11), Proteus vulgaris and Morganella morganii hemolysins (12), aerolysin from Aeromonas hydrophila $(13,14)$, gramicidin A from Bacillus brevis and alamethicin from Trichoderma viride (15), melittin $(16,17)$, and sticholysin from the sea anemone Stichodactyla helianthus (18) have all induced channel formation in lipid membranes.

In the present report we describe the occurrence of a channel-forming compound in an amphibian skin secretion. The skin secretion of the caecilian $S$. paulensis has been shown to contain a hemolytic substance (3). This skin secretion was able to form

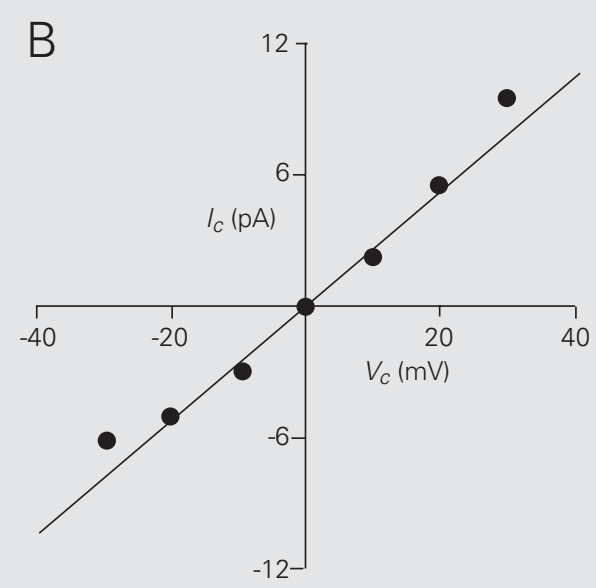

Figure 2. A, An example of the effect of $V_{c}$ on the open probability (Po) in asymmetrical solutions for sodium and potassium. The channel is virtually closed at positive voltages. B, Typical single-channel current $\left(I_{c}\right)$ vs clamped voltage $\left(V_{c}\right)$ relation in asymmetrical solutions for $\mathrm{Na}^{+}$ and $\mathrm{K}^{+}$. The average singlechannel conductance was 258 $\pm 41.67 \mathrm{pS}$. Buffered salt solutions: $150 \mathrm{mM} \mathrm{KCl}, 15 \mathrm{mM} \mathrm{NaCl}$ plus $100 \mu \mathrm{M} \mathrm{CaCl}_{2}$ on the cisside, and $150 \mathrm{mM} \mathrm{NaCl}, 15 \mathrm{mM}$ $\mathrm{KCl}$ plus $100 \mu \mathrm{M} \mathrm{CaCl}_{2}$ on the trans-side. 
voltage-dependent channels in azolectin membranes. Although S. paulensis hemolysin has not yet been purified, we suggest that the mechanism of red blood cell lysis involves the insertion of the hemolysin in the membrane and channel formation.

As can be seen in Figure 1, the addition of $S$. paulensis skin secretion to the lipid bilayer resulted in the incorporation of voltage-dependent channels with unitary conductances of $258 \pm 41.67 \mathrm{pS}$. It can also be observed that for null electrical gradients the current is zero. This probably means that i) the channel is specific for chloride, ii) it does not discriminate between sodium and potassium, having the same conductance for these two cations, or iii) the channel is closed at this voltage. The probability of the channels to be open was found to be voltage-dependent (Figure 2A). At close to zero and positive voltages the open probability is minimal. Additions of ion channel blockers such as TEA and SITS did not modify the open probability. The experimental protocol used does not permit to characterize the channel. It suggests, however, that this could be a chloride channel which would not be blocked by SITS, or a cation channel that does not discriminate between $\mathrm{Na}^{+}$and $\mathrm{K}^{+}$ions .

Further studies are necessary to purify and isolate the hemolytic compound and clarify the ion selectivity and mechanism of action of the channel-forming compound found in the skin secretion of $S$. paulensis.

\section{Acknowledgments}

The authors thank Dr. Mark Wilkinson for identifying Siphonops paulensis and reviewing this manuscript.

\section{References}

1. Clarke BT (1997). The natural history of the amphibian skin secretions, their normal functioning and potential medical applications. Biological Reviews, 72: 365-379.

2. Sawaya P (1940). Sobre o veneno das glândulas cutâneas, a secreção e o coração de Siphonops annulatus. Boletim da Faculdade de Philosophia Ciências e Letras da Universidade de São Paulo, 4: $207-270$.

3. Schwartz EF, Schwartz CA \& Sebben A (1998). Occurrence of hemolytic activity in the skin secretion of the caecilian Siphonops paulensis. Natural Toxins, 6: 179-182.

4. Schwartz EF, Schwartz CA, Sebben A, Largura SWR \& Mendes EG (1999). Indirect cardiotoxic activity of the caecilian Siphonops paulensis (Gymnophiona, Amphibia) skin secretion. Toxicon, 37: 4754.

5. Lowry OH, Rosebrough NJ, Farr A \& Randall RJ (1951). Protein measurement with the Folin phenol reagent. Journal of Biological Chemistry, 193: 256-275.

6. Christensen B, Fink J, Merrifield RB \& Mauzerall D (1988). Channelforming properties of cecropins and related model compounds incorporated into planar lipid membranes. Proceedings of the $\mathrm{Na}$ tional Academy of Sciences, USA, 85: 5072-5076.

7. Kerr ID, Dufourcq J, Rice JA, Fredkin DR \& Sansom MSP (1995). Ion channel formation by synthetic analogues of staphylococcal $\delta$-toxin. Biochimica et Biophysica Acta, 1236: 219-227.

8. Maier E, Reinhard N, Benz R \& Frey J (1996). Channel-forming activity and channel size of the RTX toxins Apxl, ApxIl, and ApxIII of Actinobacillus pleuropneumoniae. Infection and Immunity, 64: 44154423.

9. Benz R, Maier E, Ladant D, Ullmann A \& Sebo P (1994). Adenylate cyclase toxin (CyaA) of Bordetella pertussis. Evidence for the formation of small ion-permeable channels and comparison with HlyA of Escherichia coli. Journal of Biological Chemistry, 269: 27231-27239.
10. Menzl K, Maier E, Chakraborty T \& Benz R (1996). HlyA hemolysin of Vibrio cholerae $\mathrm{O} 1$ biotype El Tor. Identification of the hemolytic complex and evidence for the formation of anion-selective ion-permeable channels. European Journal of Biochemistry, 240: 646-654.

11. Döbereiner A, Schmid A, Ludwig A, Goebel W \& Benz R (1996). The effects of calcium and other polyvalent cations on channel formation by Escherichia coli $\alpha$-hemolysin in red blood cells and lipid bilayer membranes. European Journal of Biochemistry, 240: 454-460.

12. Benz R, Hardie KR \& Hughes C (1994). Pore formation in artificial membranes by the secreted hemolysins of Proteus vulgaris and Morganella morganii. European Journal of Biochemistry, 220: 339347.

13. van der Goot FG, Pattus F, Wong KR \& Buckley JT (1993). Oligomerization of the channel-forming toxin aerolysin precedes insertion into lipid bilayers. Biochemistry, 32: 2636-2642.

14. Rossjohn J, Raja SM, Nelson KL, Feil SC, van der Goot FG, Parker MW \& Buckley JT (1998). Movement of a loop in domain 3 of aerolysin is required for channel formation. Biochemistry, 37: 741746 .

15. Hanke W \& Schlue WR (1993). Planar Lipid Bilayers. Methods and Applications. Academic Press, London, UK.

16. Tosteson MT, Alvarez O \& Tosteson DC (1985). Melittin is able to form anion-seletive channels in lipid bilayers. Regulatory Peptides, 13: $39-45$.

17. Kempf C, Klausner RD, Weinstein JN, Renswoude JV, Pincus M \& Blumenthal R (1982). The effects of melittin in planar lipid bilayers. Journal of Biological Chemistry, 257: 2469-2476.

18. Tejuca M, Serra MD, Ferreras M, Lanio ME \& Menestrina G (1996). Mechanisms of membrane permeabilization by sticholysin I, a cytolysin isolated from the venom of the sea anemone Stichodactyla helianthus. Biochemistry, 35: 14947-14957. 